\title{
A Novel Biosensor to Detect MicroRNAs Rapidly
}

\author{
Jie-Ying Liao, ${ }^{1,2}$ James Q. Yin, ${ }^{1}$ and Jia-Chang Yue ${ }^{1}$ \\ ${ }^{1}$ National Laboratory of Biomacromolecules, Institute of Biophysics, Chinese Academy of Sciences, Beijing 100101, China \\ ${ }^{2}$ Center for Infection and Immunity, Institute of Biophysics, Graduate School of the Chinese Academy of Sciences (CAS), \\ Beijing 100080, China \\ Correspondence should be addressed to James Q. Yin, jqwyin@ibp.ac.cn and Jia-Chang Yue, yuejc@sun5.ibp.ac.cn
}

Received 6 January 2009; Revised 13 May 2009; Accepted 9 July 2009

Recommended by Wojtek Wlodarski

\begin{abstract}
$\delta$-free $F_{0} F_{1}$-ATPase within chromatophore was constructed as a novel biosensor to detect miRNA targets. Specific miRNA probes were linked to each rotary $\beta$ subunits of $F_{0} F_{1}$-ATPase. Detection of miRNAs was based on the proton flux change induced by lightdriven rotation of $\delta$-free $F_{0} F_{1}$-ATPase. The hybridization reaction was indicated by changes in the fluorescent intensity of $\mathrm{pH}$ sensitive CdTe quantum dots. Our results showed that the assay was attomole sensitivities $\left(1.2 \times 10^{-18} \mathrm{~mol}\right)$ to target miRNAs and capable of distinguishing among miRNA family members. Moreover, the method could be used to monitor real-time hybridization without any complicated fabrication before hybridization. Thus, the rotary biosensor is not only sensitive and specific to detect miRNA target but also easy to perform. The $\delta$-free $F_{0} F_{1}$-ATPase-based rotary biosensor may be a promising tool for the basic research and clinical application of miRNAs.
\end{abstract}

Copyright ( 2009 Jie-Ying Liao et al. This is an open access article distributed under the Creative Commons Attribution License, which permits unrestricted use, distribution, and reproduction in any medium, provided the original work is properly cited.

\section{Introduction}

MicroRNAs (miRNAs) are small noncoding RNA molecules 20-22 nucleotides $(n t)$ in length, which function to regulate gene expression. Recent studies have found that some miRNAs have altered expression in cancer cells, and specific alterations in miRNA expression may be an important biomarker for toxins which have serious effects on human health [14]. The effective detection is crucial for better understanding the roles of miRNAs in cancer cells, the response of cells to stress, and the process of cellular growth, proliferation, and metabolism. Therefore, many different methodologies have been used to profile miRNA expression, including Northern blotting with radio-labeled probes $[5,6]$, oligonucleotide microarrays $[7,8]$, and quantitative PCR-based amplification of precursor or mature miRNAs $[9,10]$. However, the normal detection approaches require many steps such as enrichment, reverse transcription, amplification, labeling, and clean-up [11]. Most of these methods are time consuming due to ovenight hybridization reaction and complicated fabrication. The most popular approaches to hybridization analysis such as Northern blotting and microarrays take a long time for hybridization of probes and their target molecules because of the static hybridization kinetics on a solid phase. To solve this problem, microfluidics technology has been used to stir the hybridization solution to increase the rate of diffusion for rapid identification $[12,13]$. For instance, the hybridization time of Surface Acoustic Wave (SAW) microagitation chips can be reduced and signal intensities increased more than 6 fold [14]. Thus, methods for rapid measuring the expression profiles of miRNAs will considerably accelerate the field in addition to the sensitivity and specificity.

Recent advances in nanotechnology have enabled the biosensor design and production of a variety of nanodevices for biological purpose. It is well known that $F_{0} F_{1}$-ATPase is a complex of two parts, $F_{0}\left(a_{1} b_{2} c_{n}\right)$ and $F_{1}\left(\alpha_{3} \beta_{3} r_{1} \delta_{1} \varepsilon_{1}\right)$. It is connected by a central stalk composed of $\gamma$ and $\varepsilon$ subunits and a peripheral stalk made of the $\delta$ and $b$ subunits. The proton translocation through $F_{0}$ drives rotation of the $c$-ring oligomer together with $r \varepsilon$ complex, forcing conformational changes in $F_{1}$, which result in ATP synthesis from ADP and $\mathrm{Pi}[15,16]$. It is also known that the $\delta$-subunit plays a switch role between the $F_{0}$ and $F_{1}$ in the ATP synthesis [17]. The $\delta$ free $F_{o} F_{1}$-ATPase is constructed with $a_{3}, b_{3}, \varepsilon$, and $\gamma$ as well as $c_{n}$ subunits as rotator and $a, b_{2}$ as stator. Based on this, $\mathrm{Su}$ et al. constructed a nanomotor by using $\delta$-free $F_{o} F_{1}$-ATPase within chromatophores [18]. 
Here, we developed a rapid method to detect miRNAs using the rotary nanoscale biosensor based on $\delta$-free $F_{0} F_{1}$ ATPase. The miRNA probe system, which was linked to the rotary $\beta$ subunit of $F_{0} F_{1}$-ATPase, was used to detect their target miRNAs. CdTe quantum dots- (QDs-) labeled chromatophores were responding to change of proton concentration of outside surface. In our experiments, miRNA probes linked to $\beta$ subunit act as a rotary propeller. By this procedure, it is possible to monitor a real-time hybridization between the immobilized miRNA probes and the stirred target miRNAs. In addition, the procedure does not require enrichment, reverse transcription, amplification, and hybridization before detection. In this study, the method is sensitive to attomole of mir-145 $\left(1.2 \times 10^{-18} \mathrm{~mol}\right)$ and is capable of discriminating a single base difference among let7 family members.

\section{Materials and Methods}

2.1. Materials. The water-soluble and $\mathrm{pH}$-sensitive $\mathrm{CdTe}$ quantum dots (QDs) were gifts from Professor Tang Fangqiong (Technical Institute of Physics and Chemistry, Chinese Academy of Sciences, China). In this study, we used the QDs with maximum emission wavelength at $535 \mathrm{~nm}$. ATP and streptavidin were purchased from SigmaAldrich (USA). Biotin-(AC5)2Sulfo-OSu was purchased from Dojindo (Japan). Lipidbiotin was purchased from Avanti. The $\delta$-free ATPase within chromatophores was prepared as the previous study $[18,19]$. The $\beta$-subunit of $F_{0} F_{1}$-ATPase was expressed and purified as described previously [20]. The antibody was prepared according to the procedure [21]. Mir-145 probe sequence is $5^{\prime}$-GGGGAUUCCUGGAAACUGC- $3^{\prime}$. The other probe sequences follow as let-7a (5'-AACTATACAATCTACTACCTTATCCT-3'), let-7a ( $5^{\prime}$-UGAGGUAGUAGGUUGUAUAGUU- $\left.3^{\prime}\right)$, let-7 $b$ ( $5^{\prime}$-UGAGGUAGUAGGUUGUGUGGUU-3'), let-7c (5'UGAGGUAGUAGGUUGUAUGGUU- $\left.3^{\prime}\right)$, and let-7d ( $5^{\prime}$ AGAGGUAGUAGGUUGCAUAGU-3'), respectively. Total RNA was extracted from MCF-7 human breast cancer cells by using TRIZOL reagent (Invitrogen) according to the manufacturer's instructions. All other analytically purified reagents are of analytical grade.

2.2. Cell Culture. The MCF-7 human breast cancer cell was kindly provided by Professor Jianwen Chen. Cells were maintained in Dulbecco's modified Eagle's medium (Sigma) supplemented with $10 \%$ fetal bovine serum $(\mathrm{PAA})$ at $37^{\circ} \mathrm{C}$ in a humidified $5 \% \mathrm{CO}_{2}$ incubator.

2.3. Biosensor Assembly and miRNA Detection. The surface of chromatophores was labeled by QDs according to [22]. Briefly, the chromatophores $(100 \mu \mathrm{L})$ were resuspended in buffer A ( $50 \mathrm{mM}$ tricine- $\mathrm{NaOH}, 5 \mathrm{mM} \mathrm{MgCl}_{2}, 10 \mathrm{mM} \mathrm{KCl}$, $\mathrm{pH}$ 6.5) and incubated for 3 hours at room temperature with $100 \mu \mathrm{L}$ CdTe QDs $\left(1 \times 10^{15} / \mu \mathrm{L}\right.$, dissolved in water $)$. Free QDs were washed away by centrifuging at $13000 \mathrm{rpm}$ for 30 minutes at $4^{\circ} \mathrm{C}$ in three times. The precipitate (QD-labeled chromatophores) was re-suspended in $100 \mu \mathrm{L}$ of $50 \mathrm{mM}$ tricine buffer ( $\mathrm{pH}$ 6.5). Meanwhile, $2 \mu \mathrm{L}$ of $2 \mu \mathrm{M}$ biotin was

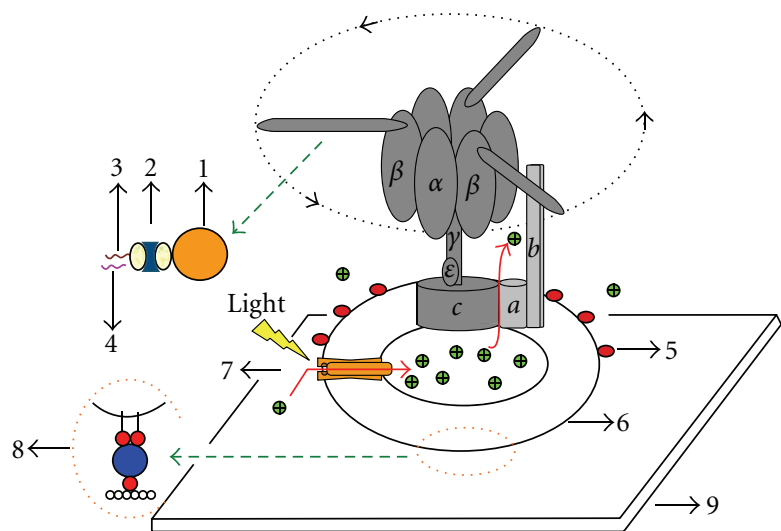

FIgURE 1: Schematic diagram of the biosensor based on $F_{0} F_{1}$ ATPase within chromatophore. 1, 2, 3, 4, 5, 6, 7, 8, and 9 represent the antibody against $\beta$ subunit, the linking system composed of [biotin-AC5-sulfo-OSu]-streptavidin-[biotin-AC5-sulfoOSu], miRNA probe, target miRNA, $535 \mathrm{~nm}$ QDs, chromatophore, bacteriorhodopsins (BRs), the linking system of lipidbiotinstreptavidin-[biotin-AC5-sulfo-OSu]-Polylysine, and the glass surface, respectively.

added in $20 \mu \mathrm{L} \beta$ subunit antibody at room temperature for 30 minutes, followed by adding $2 \mu \mathrm{L}$ of $2 \mu \mathrm{M}$ streptavidin at room temperature for 30 minutes. The streptavidin-biotinlabeled $\beta$-subunit antibody was incubated with $5 \mu \mathrm{L}$ QDslabeled chromatophores fixed on the glass slips at $37^{\circ} \mathrm{C}$ for 1 hour. Redundant free biotin-streptavidin-labeled $\beta$-subunit antibody was rinsed with $50 \mathrm{mM}$ TSM buffer $(50 \mathrm{mM}$ Tricine- $\mathrm{NaOH}$ pH 7.0, $0.25 \mathrm{M}$ sucrose, and $4 \mathrm{mM} \mathrm{MgCl}_{2}$ ). Then $100 \mu \mathrm{L} 10 \mu \mathrm{M}$ miRNA probe labeled with biotin was added and incubated at room temperature for 30 minutes. Free probes were washed out by $50 \mathrm{mM}$ TSM buffer. The $\delta$-free $F_{0} F_{1}$-ATPase with chromatophore was immobilized onto the glass surface through the biotin-streptavdin-biotin attachment. MiRNA probe system was hybridized with miRNA target in $100 \mu \mathrm{L}$ formamide hybridization solution at $37^{\circ} \mathrm{C}$. Before the detection, the sample was exposed under the cooled light source with a $570 \mathrm{~nm}$ filter for one hour to initiate the rotation of the $F_{0} F_{1}$-ATPase. During illumination, the buffer containing $2 \mathrm{mM} \mathrm{NaN}_{3}$ and 2 mMATP was infused into the chamber to inhibit the hydrolysis activity of the $F_{0} F_{1}$-ATPase and hold force between the $\beta_{3}$ and $\gamma$ to tightly band them together $[18,19,23]$. The hybridized reaction was recorded by our detection platform (BPCL) (see Supplementary Materials available online at doi: $10.1155 / 2009 / 671896)$. Fluorescence was excited at $471 \mathrm{~nm}$ and emitted at $535 \mathrm{~nm}$.

2.4. Data Analysis. The data were presented as means \pm standard deviation of the mean. All experimental data were from average of at least 4-6 independent tests.

\section{Results}

3.1. Rotary Biosensor Design. Figure 1 showed the scheme of a novel rotary biosensor based on $F_{0} F_{1}$-ATPase within 
a chromatophore. Chromatophores were immobilized to glass surface by lipidbiotin-streptavidin-biotin-Polylysine system [18]. Each $\beta$ subunit of $F_{0} F_{1}$-ATPase was linked with a miRNA probe, which was used to detect target miRNA. Thus, three target miRNAs can bind specifically to a single $F_{0} F_{1}$ ATPase. After illumination, the chromatophores can maintain the proton electrochemical gradient across the plasma membrane for a long time (see Supplementary Materials). The light-driven rotation of $F_{0} F_{1}$-ATPase 1 resulted that the protons are pumped out of chromatophores and the proton concentration around chromatophores increased $[15,16]$, which leads to an enhancement of fluorescent intensity of CdTe quantum dots (QDs). The $\mathrm{pH}$-sensitive QDs labeled on the outer surface of chromatophores are used as a proton sensor to detect proton flux [22]. Based on this, the changes of fluorescent intensity can indicate the alteration of $\mathrm{H}^{+}$ concentration $\left(\left[\mathrm{H}^{+}\right]\right)$. When target miRNAs bind to the capture probes, the rotation of $\delta$-free $F_{0} F_{1}$-ATPase slows down, which leads to a decrease in fluorescent intensity. In the course of detecting target miRNAs, miRNA probes linked to $\beta$ subunits function as a rotary propeller to stir the sample solution, which results in dynamic hybridization reaction. The rotation of $\delta$-free $F_{0} F_{1}$-ATPase-based biosensors enables one to monitor hybridization reactions in real time. In our experiment, the hybridization reaction is detected by recording the changes of fluorescence intensity. Using this method, the results can be obtained in 500 seconds.

3.2. Sensitivity and Detection Rang of miRNA Assay with Dynamic Hybridization Reaction. To determine the sensitivity of the method with dynamic hybridization property, we used miRNA (mir-145) probes to capture their target miRNAs in a complex RNA background and the change of fluorescence intensity was detected. The low limit of detection for the assays was found to be $1.2 \times 10^{-18} \mathrm{~mol}$ $\left(0.72 \times 10^{6}\right.$ molecules) (see Supplementary Materials). Figure 2(a) showed the fluorescence intensity changes of biosensors with the different amounts of loads at $37^{\circ} \mathrm{C}$, respectively. The no miRNA loading as control shows the low limit of detection. Serial 10-fold dilution of total RNA extracted from MCF-7 cells was used to analyze the detection range of the biosensors. The rate of fluorescence changes in 500 seconds were approximately $563.94 \pm 9.68 \mathrm{U} / \mathrm{s}$, $554.08 \pm 9.95 \mathrm{U} / \mathrm{s}, \quad 531.73 \pm 10.97 \mathrm{U} / \mathrm{s}, \quad 517.06 \pm 4.19 \mathrm{U} / \mathrm{s}$, $501.29 \pm 10.05 \mathrm{U} / \mathrm{s}, 487.66 \pm 6.95 \mathrm{U} / \mathrm{s}$ and $471.27 \pm 5.94 \mathrm{U} / \mathrm{s}$ for biosensor hybridized with miRNA probe, miRNA from 10 cells, $10^{2}$ cells, $10^{3}$ cells, $10^{4}$ cells, $10^{5}$ cells and $10^{6}$ cells, respectively. Using this novel rotary biosensor, we were able to detect not only amounts of relatively abundant miRNAs but also low level miRNAs because we observed a broad range of miRNAs expression levels from $1.2 \times 10^{-18} \mathrm{~mol}$ $\left(0.72 \times 10^{6}\right.$ molecules $)$ to $1.2 \times 10^{-13} \mathrm{~mol}\left(0.72 \times 10^{11}\right.$ molecules). Compared to changes in fluorescence intensity of miR-145 from $10^{6}$ cells, more miRNAs did not lead to the further changes because of the quantitative limitation of chromatophores. Increase of quantity of chromatophores can obtain a broader detection range. As shown in Figure 2(b), the rate of fluorescence changes in 500s of the different molecules is linear, and the detection range is about
5 orders of magnitude, which implies that this method can be used to quantify miRNAs with a wide range.

\subsection{Specificity of miRNA Assay with Dynamic Hybridization} Reaction. Figure 3 showed the Specificity of miRNA assay with dynamic hybridization reaction by the four let-7 family members. It is well known that Most human miRNAs differ by three or more nucleotide bases, but function as the different roles in cancer cells and the process of cellular growth, proliferation, and metabolism. In the let-7 family, the members differ by only one or two nucleotide base. To determine whether our miRNA assay is capable of discrimination among family members under the condition of dynamic hybridization, we attempted to use let-7a probes to capture let-7a, let-7b, let-7c, or let-7d miRNA targets in $1 \mathrm{pM}$. The fluorescence intensity changes of let-7a binding to the let-7a probes (the rate of fluorescence change in 500 seconds: $471.36 \pm 10.17 \mathrm{U} / \mathrm{s}$ ) was relatively slight compared with that of the biosensor only loaded with miRNA probe (the rate of fluorescence change in 500 seconds: $559.96 \pm 7.05 \mathrm{U} / \mathrm{s})$, which indicated a specific binding to let7 miRNA target (Figure 3). In contrast, the fluorescence intensity changes of let-7b, let-7c, and let-7d binding to the let-7a probes (the rate of fluorescence change in 500 seconds: $553.14 \pm 10.07 \mathrm{U} / \mathrm{s}, 549.42 \pm 9.97 \mathrm{U} / \mathrm{s}$ and $552.99 \pm 8.94 \mathrm{U} / \mathrm{s}$ ) were more dramatic than that of let-7a binding to the let$7 a$ probes and were similar to that of biosensor only loaded with miRNA probe. These results suggest that the rotary biosensor can be used to discriminate among the four let-7 family members.

3.4. Comparative Analysis of Dynamic and Static Hybridization Reaction. The normal hybridization procedure fails to move solution volumes, and so this static hybridization reaction requires incubation over night. To demonstrate utility of the static hybridization, Figure 4 shows that the fluorescence intensity changes of biosensors were hybridized with miRNA target in $100 \mu \mathrm{L}$ formamide hybridization solution at $37^{\circ} \mathrm{C}$ for 1 hour, 6 hours, and 12 hours, respectively. Before the detection, the sample in the buffer containing $2 \mathrm{mM} \mathrm{NaN}_{3}$ and 2 mMATP was exposed to the cooled light source with a $570 \mathrm{~nm}$ filter for 1 hour to initiate the rotation of the $F_{o} F_{1}$-ATPase. Then, the results of static hybridization were recorded by our detection platform. Compared to the control only loaded with miRNA probe $(565.89 \pm 5.19 \mathrm{U} / \mathrm{s})$, no significant binding signal was observed when hybridized with miRNA target for 1 hour $(555.57 \pm 8.15 \mathrm{U} / \mathrm{s})$. These data suggested that the static hybridization was strongly correlated with the incubation time, which is consistent with previous study. The biosensor with dynamic hybridization $(469.87 \pm 8.01 \mathrm{U} / \mathrm{s})$ can capture more target miRNAs than the biosensor with static hybridization for 6 hours $(511.47 \pm 10.01 \mathrm{U} / \mathrm{s})$. But, upon static hybridization for 12 hours $(451.90 \pm 7.61 \mathrm{U} / \mathrm{s})$, the rate of fluorescence changes was just slighter than that in of dynamic hybridization $(469.87 \pm 8.01 \mathrm{U} / \mathrm{s})$. The activity of $\delta$ free $F_{0} F_{1}$-ATPase did not change because of the overnight hybridization reaction (data not shown). In comparison with 


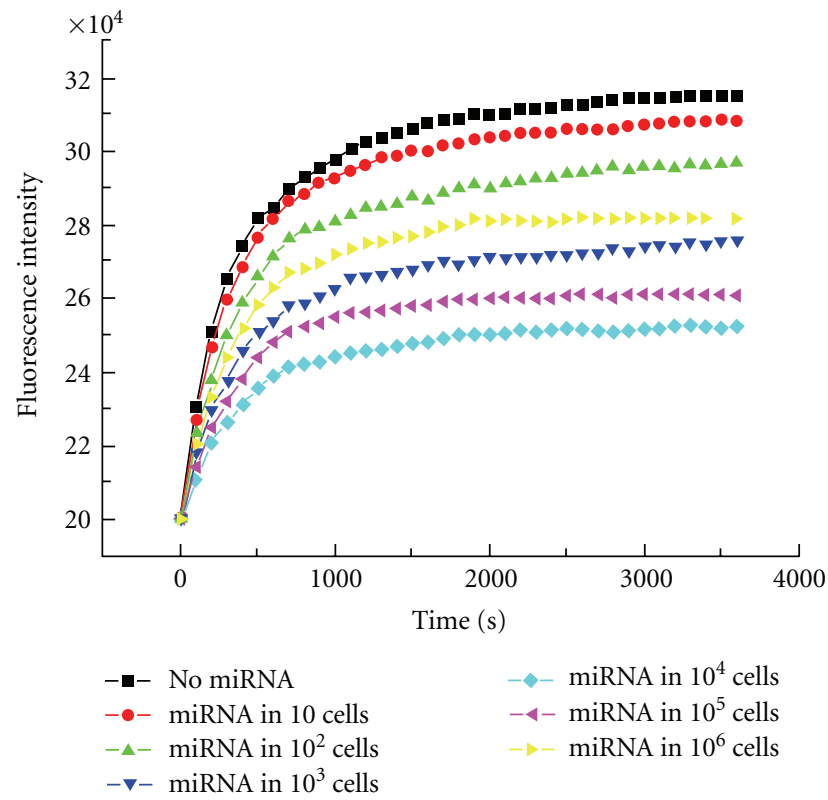

(a)

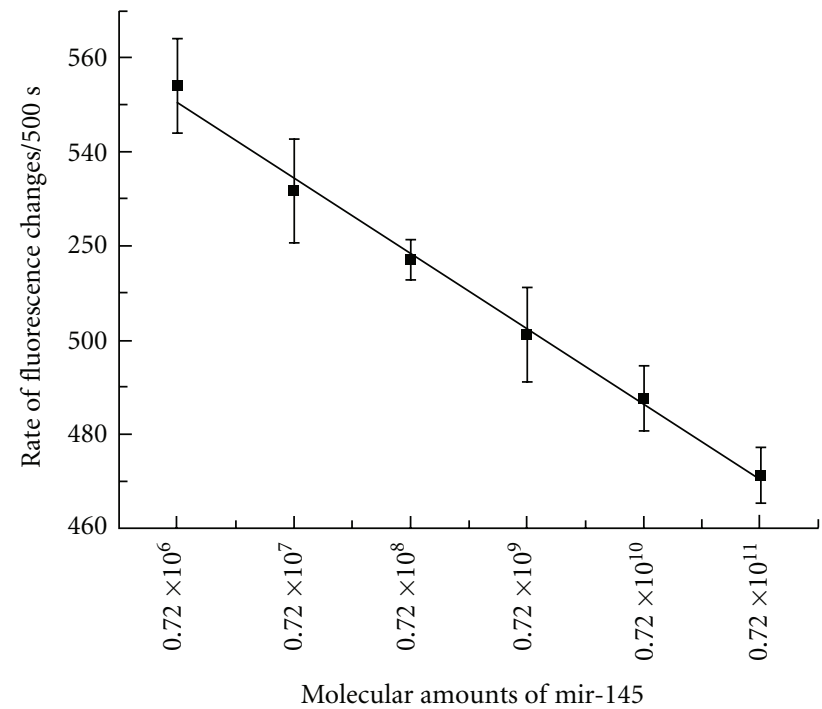

(b)

FIGURE 2: Detection range of the miRNA biosensor assay with dynamic hybridization. (a) Total RNA extracted from MCF-7 cells was serially 10-fold diluted. Different amounts of miR-145 could be detected by the biosensor loaded without or with target miRNAs derived from 10 cells, $10^{2}$ cells, $10^{3}$ cells, $10^{4}$ cells, $10^{5}$ cells, and $10^{6}$ cells reaction at $37^{\circ} \mathrm{C}$, respectively. (b) Correlation between the rate of fluorescence changes and molecular amounts of miRNAs. The mean value was calculated from three independent detection experiments. Error bars show variations among the experiments as the standard deviation of the mean.

the static hybridization, the dynamic hybridization using the rotation of miRNA probe system will greatly reduce the time to detect target miRNAs.

\section{Discussion}

Here we present a novel method for the rapid detection of target miRNA. The miRNA probe system linked to rotary $\beta$ subunit of $\delta$-free $F_{0} F_{1}$-ATPase was used to detect target miRNA. The change of proton flux was recorded through the changes of fluorescence intensity of QDs, which can monitor real-time hybridization state [22]. In this study, the biosensor has function as a rapid, sensitive, and specific tool to detect miRNAs.

The recent miRNAs detection method has called for the rapidity of the hybridization reactions and real-time detection. In the normal hybridization reaction, the vicinity of the corresponding probe spot will take long time to finish, especially in case of low concentrated miRNA molecules. In our experiments, the rotation of $F_{0} F_{1}$-ATPase-induced fluid 


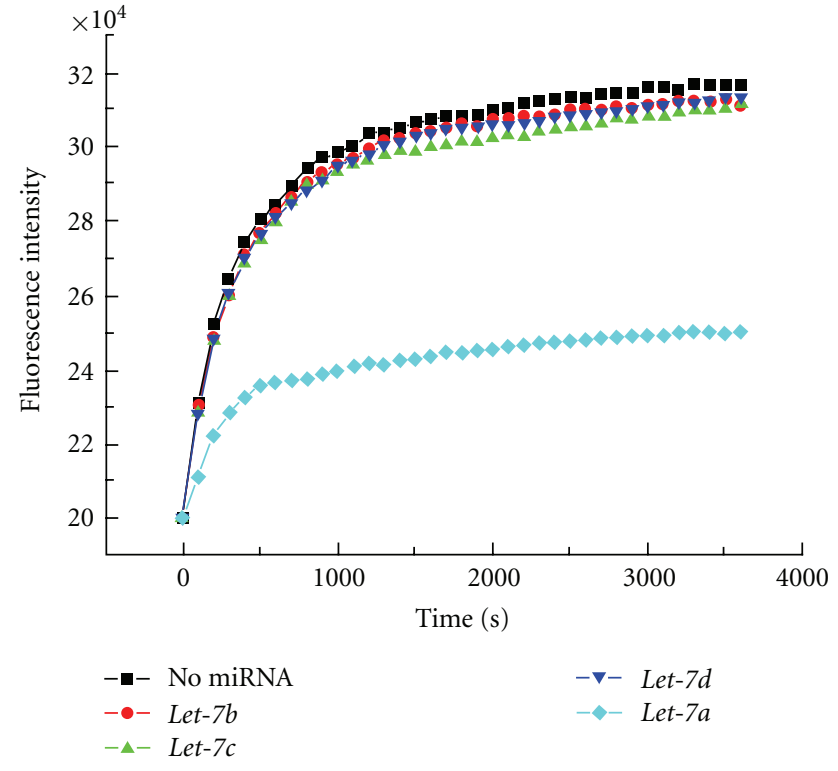

FIgURE 3: The miRNA biosensor with dynamic hybridization can be used to specifically detect the target miRNAs. The let-7a probes were used to capture their target miRNAs. The biosensor was only hybridized without any miRNAs or with incompletely complementary target let-7b, let-7c, let-7d or complete complementary target let- $7 a$ at $37^{\circ} \mathrm{C}$, respectively.

movement of nanoliter volumes could increase in collision between the probe and the target, thereby accelerating the hybridization kinetics $[24,25]$. The efficiency of biosensor with dynamic hybridization efficiency was more than that of static hybridization for 6 hours (Figure 4). Meanwhile, the rotation of $\delta$-free $F_{0} F_{1}$-ATPase makes it possible to monitor the real-time hybridization, which can yields data during the hybridization reaction. Furthermore, there is no need to reverse transcription and amplification before hybridization, thereby reducing the overall time of the detection.

The detection sensitivity was based on two lines of evidence. First, dynamic hybridization reaction might improve assay sensitivity. Peytavi et al. demonstrated that the microfluidic system increased the hybridization signal by 10 -fold compared with a static hybridization system [13]. Other groups have demonstrated that inducing a microagiation in the fluid layer on a microarray can reach the signal amplification by 6 -fold $[14,26]$. Our method was sensitive enough to detect the amounts of miRNAs in 10 MCF-7 cells. Especially, mir-145 is considered act as tumor suppressor genes or oncogenes and down-regulated in MCF7 breast cancer cell line. Second, QDs have unique optical properties and exceptional photostability according to the previous study $[27,28]$. In our experiments, more than two hundred QDs were attached on one chromatophore, which can enhance sensitivity in the process of miRNA detection (see Supplementary Material).

In terms of specificity, our method is capable of discrimination of a single base change in the target miRNAs even under particularly permissive binding condition. In

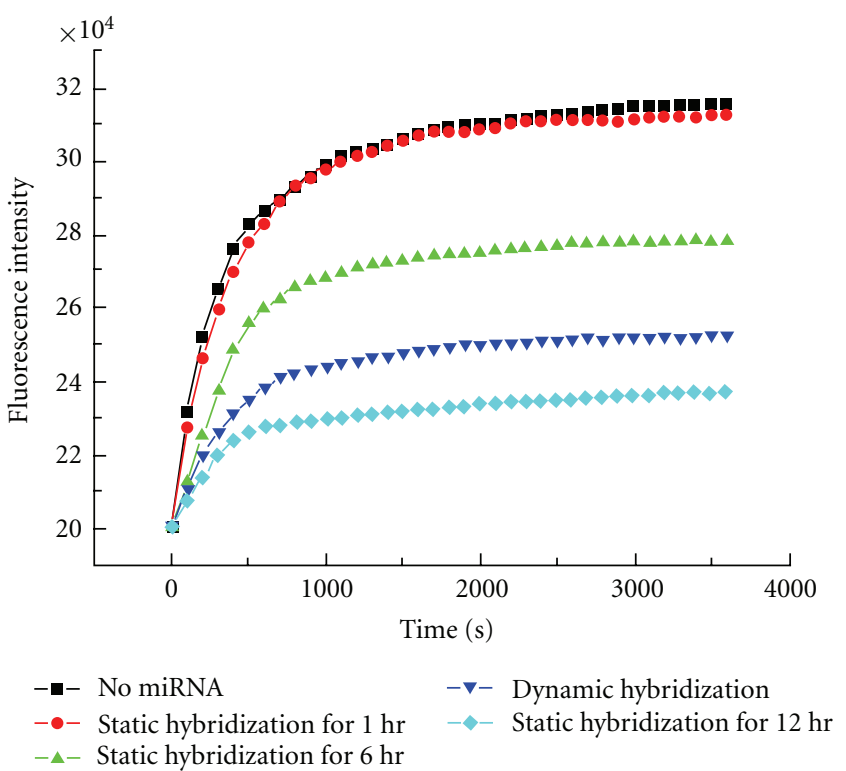

FIGURE 4: The dynamic hybridization resulted in a decrease in hybridization time. In the static hybridization, the biosensor was hybridized without or with miRNAs extracted from MCF-7 cells in the hybridization solution at $37^{\circ} \mathrm{C}$ for 1 hour, 6 hours, and 12 hours before detection, respectively. For the dynamic detection, the hybridization of biosensor and target miRNAs was monitored in real time without the preincubation with target miRNAs.

the experiments, we observed good discrimination among let-7a, let-7b, let-7c, and let-7d using let-7a-specific probes (Figure 3). During the hybridization reaction, the rotation of $\delta$-free $F_{0} F_{1}$-ATPase might decrease the binding of unspecific miRNAs. The results showed that rotary miRNA probe system tend to bind the target miRNA complementary completely to the probe sequence.

In conclusion, our results demonstrated that $\delta$-free $F_{0} F_{1}$-ATPase-based rotary biosensor is a promising research tool that can be applied to large-scale miRNAs detection combined with the lab-on-a-chip technology.

\section{Acknowledgments}

This work was supported by Grants from Basic Research Program of China National Natural Science of China (9732007CB935901), Instrument Program of Chinese Academy of Sciences (07CZ203100), and National Natural Science Foundation of China (20873176).

\section{References}

[1] M. Z. Michael, S. M. O'Connor, N. G. van Holst Pellekaan, G. P. Young, and R. J. James, "Reduced Accumulation of Specific MicroRNAs in Colorectal Neoplasia," Molecular Cancer Research, vol. 1, no. 12, pp. 882-891, 2003.

[2] G. A. Calin, C.-G. Liu, C. Sevignani, et al., "MicroRNA profiling reveals distinct signatures in B cell chronic lymphocytic leukemias," Proceedings of the National Academy of Sciences of the United States of America, vol. 101, no. 32, pp. 11755-11760, 2004. 
[3] L. He, J. M. Thomson, M. T. Hemann, et al., "A microRNA polycistron as a potential human oncogene," Nature, vol. 435, no. 7043, pp. 828-833, 2005.

[4] S. M. Johnson, H. Grosshans, J. Shingara, et al., "RAS is regulated by the let-7 microRNA family," Cell, vol. 120, no. 5, pp. 635-647, 2005.

[5] J. Jiang, E. J. Lee, Y. Gusev, and T. D. Schmittgen, "Real-time expression profiling of microRNA precursors in human cancer cell lines," Nucleic Acids Research, vol. 33, no. 17, pp. 53945403, 2005.

[6] A. M. Krichevsky, K. S. King, C. P. Donahue, K. Khrapko, and K. S. Kosik, "A microRNA array reveals extensive regulation of microRNAs during brain development," RNA, vol. 9, no. 10, pp. 1274-1281, 2003.

[7] T. D. Schmittgen, J. Jiang, Q. Liu, and L. Yang, "A highthroughput method to monitor the expression of microRNA precursors," Nucleic Acids Research, vol. 32, no. 4, p. e43, 2004.

[8] L. F. Sempere, S. Freemantle, I. Pitha-Rowe, E. Moss, E. Dmitrovsky, and V. Ambros, "Expression profiling of mammalian microRNAs uncovers a subset of brain-expressed microRNAs with possible roles in murine and human neuronal differentiation," Genome Biology, vol. 5, no. 3, p. R13, 2004.

[9] M. Sioud and Ø. Røsok, "Profiling microRNA expression using sensitive cDNA probes and filter arrays," BioTechniques, vol. 37, no. 4, pp. 574-580, 2004.

[10] A. Válóczi, C. Hornyik, N. Varga, J. Burgyán, S. Kauppinen, and Z. Havelda, "Sensitive and specific detection of microRNAs by northern blot analysis using LNA-modified oligonucleotide probes," Nucleic Acids Research, vol. 32, no. 22, p. e175, 2004.

[11] P. T. Nelson, D. A. Baldwin, L. M. Scearce, J. C. Oberholtzer, J. W. Tobias, and Z. Mourelatos, "Microarray-based, highthroughput gene expression profiling of microRNAs," Nature Methods, vol. 1, no. 2, pp. 155-161, 2004.

[12] J. A. Benn, J. Hu, B. J. Hogan, R. C. Fry, L. D. Samson, and T. Thorsen, "Comparative modeling and analysis of microfluidic and conventional DNA microarrays," Analytical Biochemistry, vol. 348, no. 2, pp. 284-293, 2006.

[13] R. Peytavi, F. R. Raymond, D. Gagné, et al., "Microfluidic device for rapid (<15 min) automated microarray hybridization," Clinical Chemistry, vol. 51, no. 10, pp. 1836-1844, 2005.

[14] A. Toegl, R. Kirchner, C. Gauer, and A. Wixforth, "Enhancing results of microarray hybridizations through microagitation.," Journal of Biomolecular Techniques, vol. 14, no. 3, pp. 197-204, 2003.

[15] P. D. Boyer, "The ATP synthase-a splendid molecular machine," Annual Review of Biochemistry, vol. 66, pp. 717-749, 1997.

[16] J. Weber and A. E. Senior, "ATP synthesis driven by proton transport in $\mathrm{F}_{0} \mathrm{~F}_{1}$-ATP synthase," FEBS Letters, vol. 545, no. 1, pp. 61-70, 2003.

[17] Y. B. Cui, Y. H. Zhang, J. C. Yue, and P. D. Jiang, "Direct observation of the clockwise light-driven rotation of $\mathrm{F}_{0} \mathrm{~F}_{1}$-ATP synthase complex," Chinese Science Bulletin, vol. 13, no. 49, pp. 1342-1347, 2004.

[18] T. Su, Y. Cui, X. Zhang, et al., "Constructing a novel Nanodevice powered by $\delta$-free $\mathrm{F}_{0} \mathrm{~F}_{1}$-ATPase," Biochemical and Biophysical Research Communications, vol. 350, no. 4, pp. 1013-1018, 2006.

[19] Z. Yinghao, W. Jun, C. Yuanbo, Y. Jiachang, and F. Xiaohong, "Rotary torque produced by proton motive force in FoF1 motor," Biochemical and Biophysical Research Communications, vol. 331, no. 1, pp. 370-374, 2005.
[20] X. Liu, Y. Zhang, J. Yue, P. Jiang, and Z. Zhang, " $\mathrm{F}_{0} \mathrm{~F}_{1}$ ATPase as biosensor to detect single virus," Biochemical and Biophysical Research Communications, vol. 342, no. 4, pp. 1319-1322, 2006.

[21] W. C. Hanly, J. E. Artwohl, and B. T. Bennett, "Review of Polyclonal Antibody Production Procedures in Mammals and Poultry," Institute of Laboratory Animal Research, vol. 37, pp. 93-118, 1995.

[22] Z. Yun, D. Zhengtao, Y. Jiachang, T. Fangqiong, and W. Qun, "Using cadmium telluride quantum dots as a proton flux sensor and applying to detect H9 avian influenza virus," Analytical Biochemistry, vol. 364, no. 2, pp. 122-127, 2007.

[23] E. Muneyuki, M. Makino, H. Kamata, Y. Kagawa, M. Yoshida, and $\mathrm{H}$. Hiata, "Inhibitory effect of $\mathrm{NaN}_{3}$ on the $\mathrm{F}_{0} \mathrm{~F}_{1}$ ATPase of submitochondrial particles as related to nucleotide binding," Biochimica et Biophysica Acta, vol. 1144, no. 1, pp. 62-68, 1993.

[24] D. Axelrod and M. D. Wang, "Reduction-of-dimensionality kinetics at reaction-limited cell surface receptors," Biophysical Journal, vol. 66, no. 3, pp. 588-600, 1994.

[25] M. K. McQuain, K. Seale, J. Peek, et al., "Chaotic mixer improves microarray hybridization," Analytical Biochemistry, vol. 325, no. 2, pp. 215-226, 2004.

[26] I. Nindl, A. Toegl, W. Sterry, and E. Stockfleth, "High sensitivity and reproducibility of immunohistochemistry with microagitation," Archives of Dermatological Research, vol. 296, no. 6, pp. 278-281, 2004.

[27] X. Wu, H. Liu, J. Liu, et al., "Immunofluorescent labeling of cancer marker Her2 and other cellular targets with semiconductor quantum dots," Nature Biotechnology, vol. 21, no. 1, pp. 41-46, 2003.

[28] W. C. W. Chan and S. Nie, "Quantum dot bioconjugates for ultrasensitive nonisotopic detection," Science, vol. 281, no. 5385, pp. 2016-2018, 1998. 

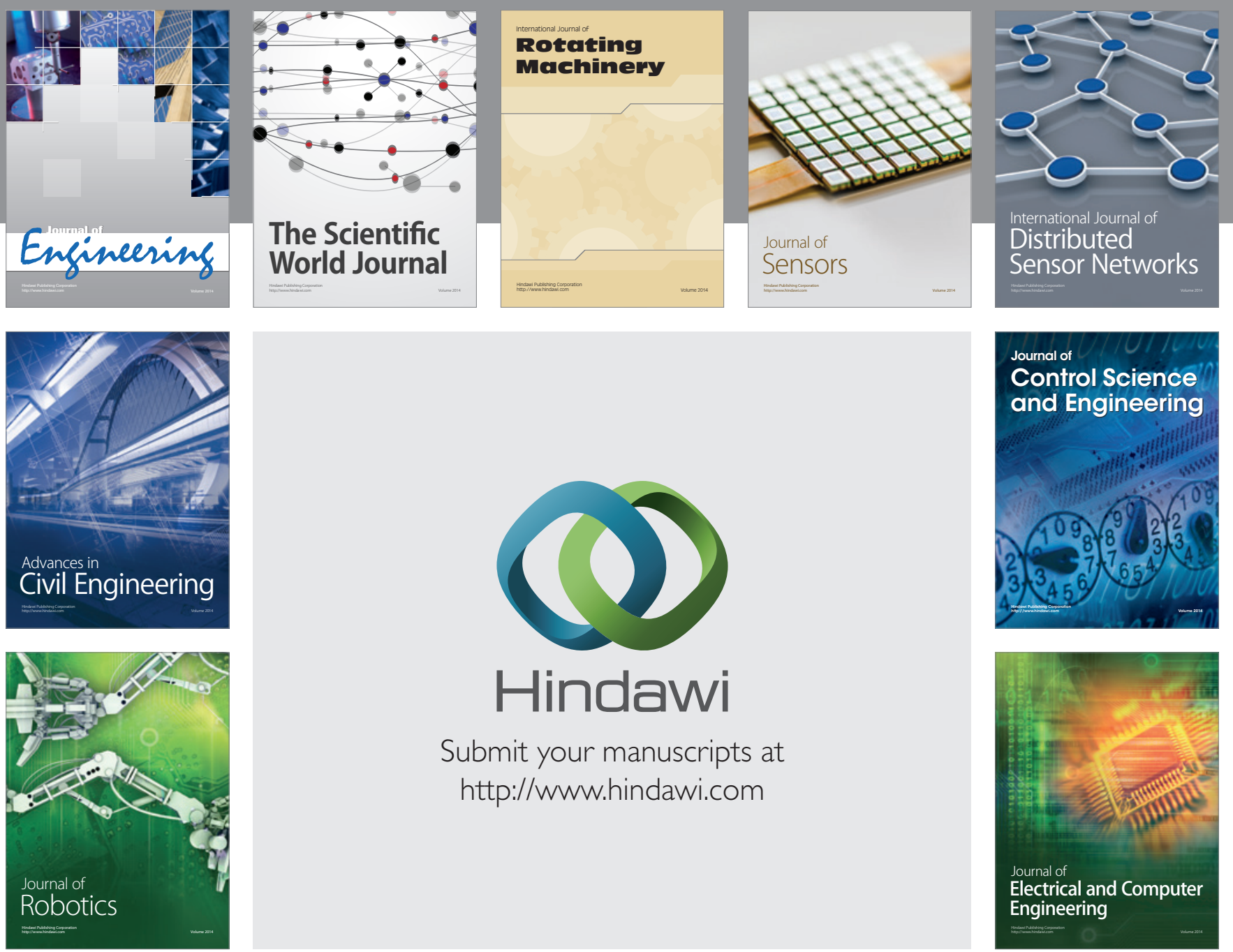

Submit your manuscripts at

http://www.hindawi.com
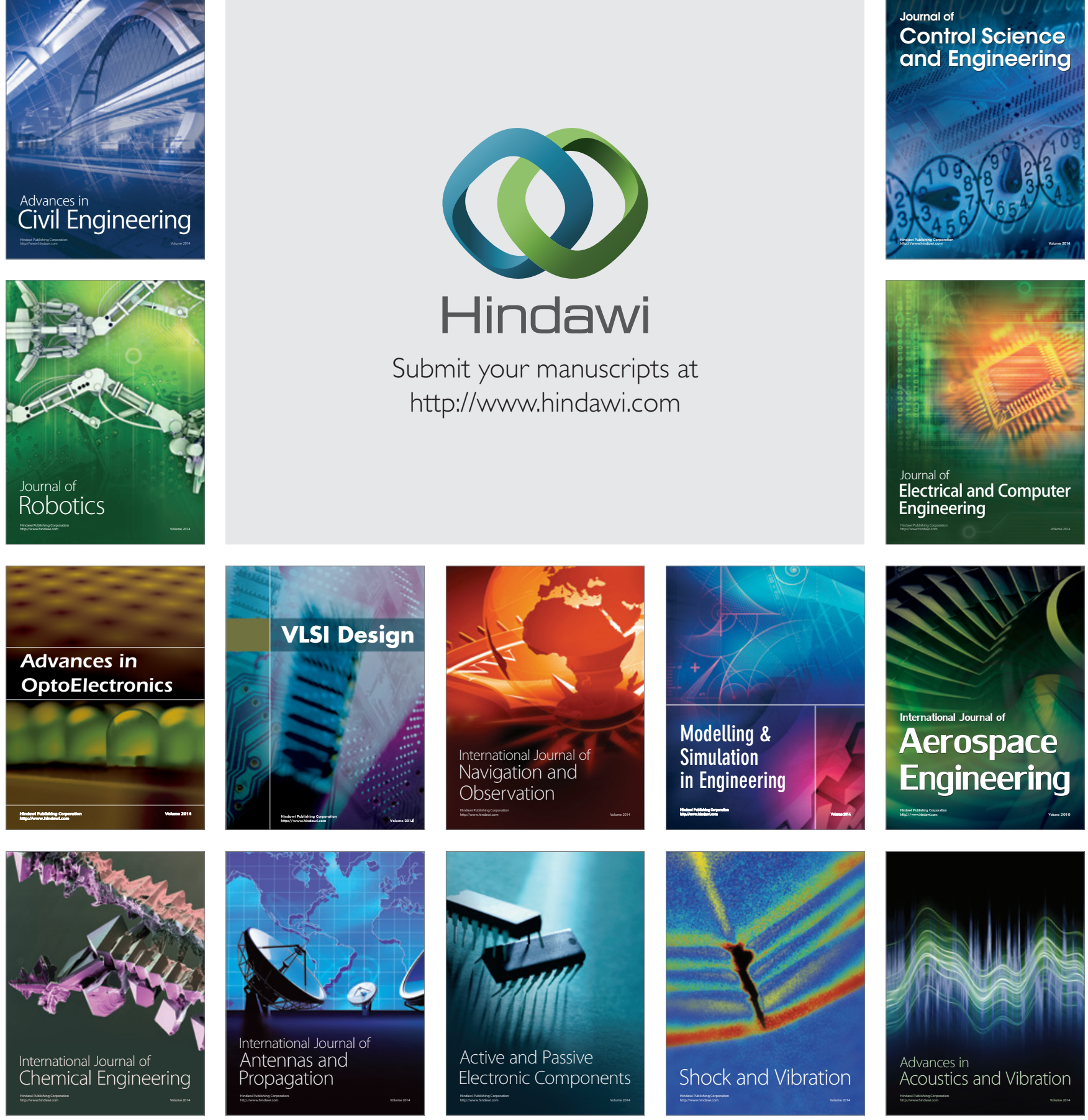